\title{
Demonstration and analysis of a steam reforming process driven with solar heat using molten salts as heat transfer fluid
}

\author{
Alberto Giaconia ${ }^{1, *}$, Giampaolo Caputo ${ }^{1}$, Primo Di Ascenzi ${ }^{1}$, Giulia Monteleone $^{1}$, and Luca $_{\text {Turchetti }}{ }^{1}$ \\ ${ }^{1}$ ENEA, Italian National Agency for New Technologies, Energy and Sustainable Economic Development, Department of Energy \\ Technologies and Renewable Sources (TERIN), Casaccia Research Center, via Anguillarese 301, 00123 Rome, Italy
}

\begin{abstract}
Solar reforming of biogas or biomethane represents an example hydrogen production from the combination of renewable sources such as biomass and solar energy. Thanks to its relatively low-cost and flexibility, solar-reforming can represent a complementary source of hydrogen where/when the demand exceeds the green hydrogen availability from water electrolysis powered by PV or wind. Molten salts can be used as heat transfer fluid and heat storage medium in solar-driven steam reforming. The main units of the process have been developed at the pilot scale and experimentally tested in a molten salt experimental loop at ENEA-Casaccia research center: a molten salt heater and a molten salt membrane reformer. After experimental validation, techno-economic studies have been carried out to assess the solar reforming technology on commercial scale and exploitation opportunities have been analysed.
\end{abstract}

\section{Introduction}

The growing interest on hydrogen requires evaluating all possible conversion processes for its production. Technologies developed so far allow hydrogen production from renewable (carbon-free or carbon-neutral) sources using electrochemical, photochemical, thermochemical or biochemical pathways; however, there are opportunities for further improvement of green hydrogen production in terms of costs reduction and efficiency in the deployment of primary sources [1].

Besides water-splitting by electrolysis driven by renewable power sources, steam reforming of biomassderived methane represents a reliable and complementary thermochemical route, provided that this heat-demanding process is supplied with renewable heat to obtain $100 \%$ "green" hydrogen.

Today, steam methane reforming is the most used industrial process for hydrogen production. The core of the reforming plants is represented by catalytic reactors where the Steam Methane Reforming (SMR) reaction (1), which is highly endothermic, and the Water Gas Shift (WGS) reaction (2), which is moderately exothermic, take place:
$\mathrm{CH}_{4}+\mathrm{H}_{2} \mathrm{O} \rightarrow \mathrm{CO}+3 \mathrm{H}_{2}$

(SMR reaction, $\Delta \mathrm{H}^{0}{ }_{298 \mathrm{~K}}=+206 \mathrm{~kJ} / \mathrm{mol}, 750-950^{\circ} \mathrm{C}$ )

$\mathrm{CO}+\mathrm{H}_{2} \mathrm{O} \rightarrow \mathrm{CO}_{2}+\mathrm{H}_{2}$

(WGS reaction, $\Delta \mathrm{H}^{0}{ }_{298 \mathrm{~K}}=-41 \mathrm{~kJ} / \mathrm{mol}, 250-450^{\circ} \mathrm{C}$ )

Process heat is mainly needed to drive the highly endothermic SMR reaction (1) and to generate the reactant steam fed to reactors (steam is the excess reactant, in order to improve the hydrocarbons conversion and prevent any carbon deposition over the SMR catalyst).

Replacing fossil methane (e.g. from natural gas) with biomass-derived methane (i.e., biomethane) as feedstock allows to apply the same process scheme to green hydrogen production. However, in order to best valorise the available biomethane (i.e., to maximize the biomethane-to-hydrogen conversion) it is possible to use other renewable heat sources to partially or totally supply the process heat. One option consists in using hightemperature solar concentrating solar thermal (CST) systems to drive the thermochemical process. In this case, the issues raised by the intermittent nature of the primary renewable source can be smoothed out by applying suitable Thermal Energy Storage (TES) systems and Heat Transfer Fluid (HTF) to steadily transfer the renewable heat to the thermochemical process.

A substantial revision of the layout of the chemical process is however required for its adaptation to the new heat source, mostly related to the lower temperature achieved in the current CST plants compared to the conventional steam reforming operating conditions. With this purpose, ENEA has developed a new process scheme to drive methane steam reforming with solar heat [2]: the solar heat from the CST system equipped with TES is transferred at constant rate to the chemical process by using a molten salt mixture $\left(\mathrm{NaNO}_{3} / \mathrm{KNO}_{3}, 60 / 40 \% \mathrm{wt}\right)$ as $\mathrm{HTF}$ at a temperature up to $550^{\circ} \mathrm{C}$. The use of a membrane reformer heated with molten salt [3] allows to overcome the hydrogen yield limitations related to such low operating temperature.

The implementation of the above-described process scheme requires innovative heat-transfer equipment, which was also developed by ENEA in previous research actions:

- a molten salt heated Steam Generator (SG);

- a molten salt heater (MSH) to guarantee the continuity of hydrogen production also during periods with low or no

*orresponding author: alberto.giaconia@enea.it 
solar irradiance by using a fuel as back-up energy source.

This paper presents the state of the art of research activities carried out by ENEA on renewable-heated steam reforming and the perspectives for process optimization to obtain cost-competitive green hydrogen production.

\section{Process description and state of the art}

Figure 1 presents a conceptual scheme of the SMR process heated with molten salts. The molten salt captures the intermittent renewable heat up to $550^{\circ} \mathrm{C}$, in a CST system. Hot molten salts are stored in a TES tank. A molten salt heater (MSH), including a gas fuel combustion chamber and a gas/molten salt heat exchanger, is used as back-up to heat the molten salt up to $550^{\circ} \mathrm{C}$ in case of lack of renewable energy from the TES system. Then, the hot molten salt stream is fed to the SMR process units. A single membrane reformer is used to carry out the SMR and WGS reactions with satisfactory final methane conversion (exceeding the value that can be obtained with a conventional reformer operating under the same conditions) thanks to the continuous removal of hydrogen from the reaction environment [2]. A pre-reformer can be included in order to feed the membrane reformer with an hydrogen-containing mixture; this ensures a better exploitation of the membrane and avoids sharp temperature gradients near the inlet section of the reactor. The residual sensible heat of the molten salt is used to generate the process steam.

Besides the outlet hydrogen permeate stream, a retentate stream is also obtained from the membrane reformer. This stream contains produced $\mathrm{CO}_{2}$ and $\mathrm{CO}$, unreacted $\mathrm{CH}_{4}$ and $\mathrm{H}_{2} \mathrm{O}$, and non-permeated $\mathrm{H}_{2}$. Depending on the operation mode, this retentate stream can be used in two different ways:

1) burnt as fuel in the MSH;

2) sent to a $\mathrm{CO}_{2}$ separation unit to recover and recycle a $\mathrm{CH}_{4} / \mathrm{H}_{2} / \mathrm{CO}$ mixture.

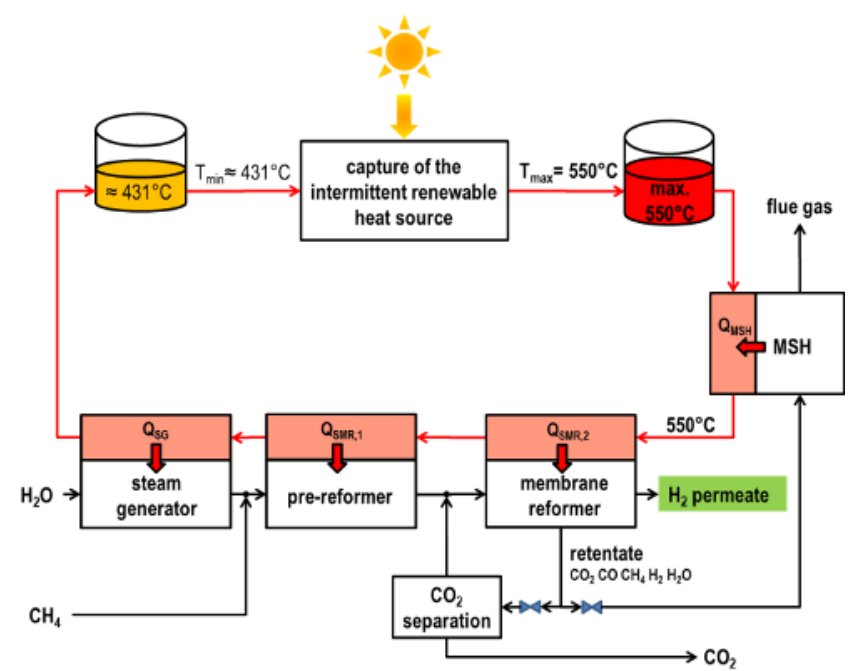

Fig. 1. Conceptual scheme of the SMR process driven with renewable heat using molten salt up to $550^{\circ} \mathrm{C}$ as heat transfer fluid. Red lines: molten salt streams; black lines: process streams.
The above described process scheme includes several innovative process units integrated in the molten salt loop: the CST system with TES, the MSH, the steam generator and the steam reformers heated with the molten salt. These key units have been individually developed and successfully tested at the pilot or pre-commercial scales by ENEA in different projects.

The molten salt heated membrane reformer integrated with the pre-reformer has been developed and successfully demonstrated at the pilot scale (up to $3 \mathrm{Nm}^{3} / \mathrm{h} \mathrm{H}_{2}$ permeate production) in a molten salt loop in the project CoMETHy $[3,4]$. Figure 2 shows the tube sheet of the molten salt heated steam reformer with catalyst and membranes in the inner tubes [4].

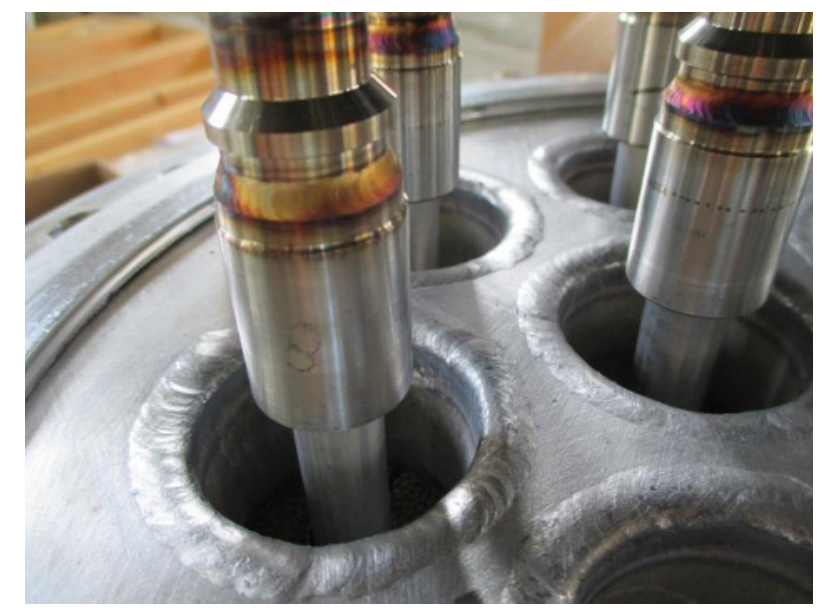

Fig. 2. Tube sheet of the molten salt heated steam reformer with catalyst and membranes in the inner tubes developed in the project CoMETHy [4].

The molten salt heater (MSH) has been developed and successfully demonstrated by ENEA in the projects MATS and Hysol: Figure 3 shows the $90 \mathrm{~kW}$ (thermal) gas/molten salt heat exchanger installed in the molten salt loop to validate heat transfer correlations prior to process scale-up [5]. In this case, gas fuels were burned in a combustion chamber and the generated hot gases up to $632^{\circ} \mathrm{C}$ used to heat the molten salt in the convective section of the back-up unit [5].

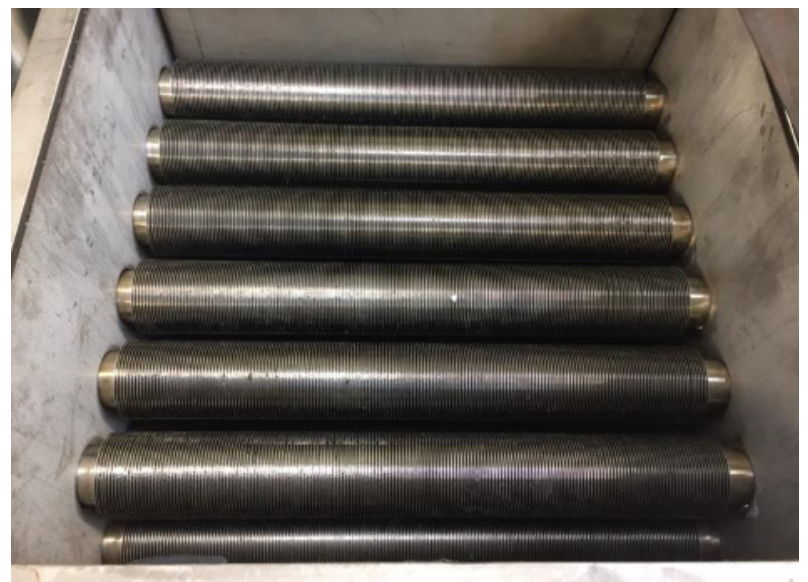

Fig. 3. Finned tube bundle of the MSH prototype developed in the projects MATS and Hysol [5]. 
Concentrating solar systems with "solar salt" and TES up to $550^{\circ} \mathrm{C}$ have been developed in several projects by different players worldwide. In the project MATS, ENEA has specifically developed and demonstrated an innovative approach that integrates the following units at the $5 \mathrm{MW}$ (thermal) scale: parabolic linear concentrators with direct solar heating of molten salt up to $550^{\circ} \mathrm{C}$, a gas fuelled $\mathrm{MSH}$, and single-tank TES integrated with a super-heated steam generator (Figure 4). The mentioned units are integrated in a cogenerative plant to produce $1 \mathrm{MW}$ of power and $250 \mathrm{~m}^{3} / \mathrm{d}$ of desalinated water [6].

The $\mathrm{CO}_{2}$ separation unit shown in Figure 1 can be based on mature technologies such as PSA or amine systems.

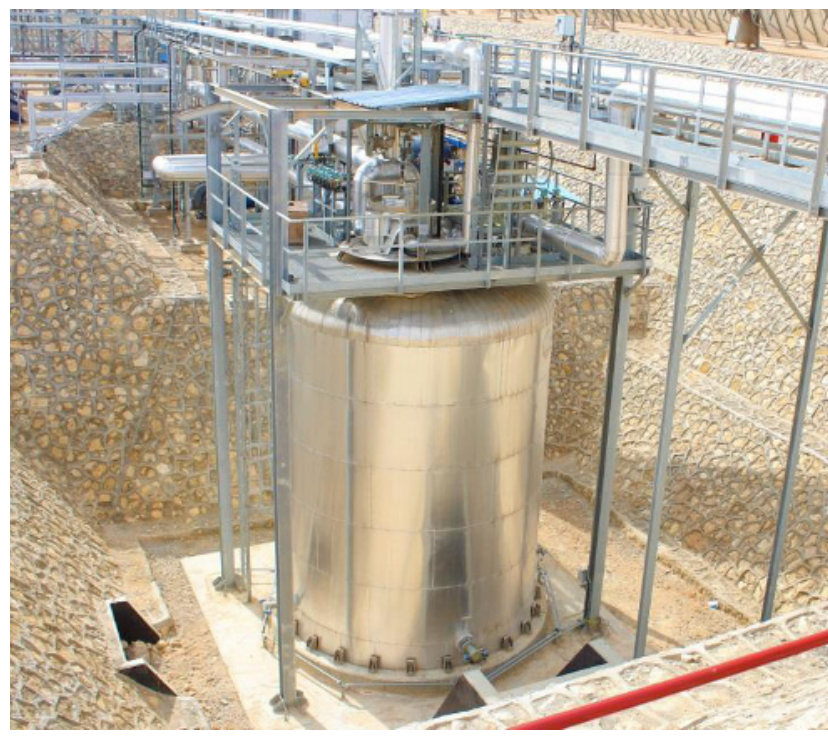

Fig. 4. Underground molten salt TES system (14 MWh thermal) integrated with super-heated steam generator developed in the project MATS [6].

\section{Development perspectives}

The previous section reports that the different units of the SMR process scheme shown in Figure 1 have been tested and validated at the pilot or demonstration scale: up to 3 $\mathrm{Nm}^{3} / \mathrm{h}$ hydrogen production for the SMR reactors and up to $5 \mathrm{MW}$ thermal for the heat supply units (solar concentrators, MSH, TES, SG). Additionally, tests carried out with the molten salt heated SMR pilot reactors did not show any significant performance loss after about 150 hours of operation [4]; however, it is worth underlying that the durability/reliability of membrane reactors has yet to be validated for at least 5,000 hours-on-stream.

Assuming a plant with $1,500 \mathrm{Nm}^{3} / \mathrm{h}$ capacity, a preliminary techno-economic assessment resulted on Levelized Costs of Hydrogen (LCOH) from 2.4 to $4.7 € / \mathrm{kg}$ for the solar SMR process [7]. This wide range is mainly due to the different assumptions made on the utilization factor and the cost of the CST plant. Table 1 summarizes the results in terms of $\mathrm{LCOH}$ and average specific $\mathrm{CO}_{2}$ emissions under different scenarios:

- "solar-only" case considers minimal use of the back-up, i.e. when solar heat is not available the hydrogen production is stopped and reactors maintained in a "hot stand-by" condition;

- "hybrid" case considers 8,000 hours/year continuous hydrogen production with broad use of the back-up system when solar heat is not available.

Clearly, the hybrid case entails combustion of the retentate during the operating hours, when solar heat is no longer available and, hence, specific $\mathrm{CO}_{2}$ emissions increase from 5.7 to $10.2 \mathrm{kgCO} / \mathrm{kg}_{\mathrm{H} 2}$ (yearly average) [7]. Compared to a conventional (non-solar) SMR process with typical overall $\mathrm{CO}_{2}$ emissions in the flue gases of 11.7 $\mathrm{kgCO}_{2} / \mathrm{kgH}_{2}$, in the solar hybrid case only 4.3 out of the total $10.2 \mathrm{kgCO} / \mathrm{kg}_{2}$ produced are emitted with the flue gases of the $\mathrm{MSH}$; the residual $\mathrm{CO}_{2}$ is recovered as nearly pure stream in a carbon capture and utilization (CCU) scenario.

Table 1 shows that a reduction of the unit costs of the CST system from 231 to $100 € / \mathrm{m}^{2}$ (installed, including solar collectors, receiver tubes, piping and ancillary equipment) will lead to a more competitive hydrogen production costs: from $2.8-4.7 € / \mathrm{kg}$ to $2.4-3.4 € / \mathrm{kg}\left(\mathrm{CH}_{4}\right.$ cost: $\sim 0.25 € / \mathrm{kg}$ ). This is due to the significant impact of the CST cost on the capital expenditure of the plant [7].

Table 1. Levelized Cost of Hydrogen and specific $\mathrm{CO}_{2}$ emissions obtained for the solar SMR under different assumptions [7].

\begin{tabular}{|c|c|c|c|c|}
\hline & \multicolumn{2}{|c|}{ yearly operation hours } \\
\hline & & & $\begin{array}{c}\text { solar-only } \\
4,456 \\
\text { hr/year }\end{array}$ & $\begin{array}{c}\text { hybrid } \\
8,000 \\
\text { hr/year }\end{array}$ \\
\hline \multirow{2}{*}{$\mathrm{LCOH}$} & \multirow{2}{*}{$\begin{array}{l}\text { CST } \\
\text { plant } \\
\text { cost }\end{array}$} & $\begin{array}{l}100 \\
€ / \mathrm{m}^{2} \\
\end{array}$ & $3.4 € / \mathrm{kgH}$ & $2.4 € / \mathrm{kg}_{\mathrm{H} 2}$ \\
\hline & & $\begin{array}{l}231 \\
€ / \mathrm{m}^{2} \\
\end{array}$ & $4.7 € / \mathrm{kgH}_{2}$ & $2.8 € / \mathrm{kgH}_{2}$ \\
\hline \multicolumn{3}{|c|}{ Specific $\mathrm{CO}_{2}$ emissions } & $\begin{array}{c}5.7 \\
\mathrm{~kg}_{\mathrm{CO} 2} / \mathrm{kg}_{\mathrm{H} 2}\end{array}$ & $\begin{array}{c}10.2 \\
\mathrm{~kg}_{\mathrm{CO} 2} / \mathrm{kg}_{\mathrm{H} 2}\end{array}$ \\
\hline
\end{tabular}

Based on these preliminary results, development pathways can be identified to further reduce the hydrogen production costs. Due to the significant impact of the CST system on the cost of hydrogen, it is recommended to investigate solutions that improve the thermal efficiency of the process. As a matter of fact, the overall thermal efficiency of the preliminary SMR scheme being around $60 \%$ [7] can be improved with an optimized thermal integration.

A major source of efficiency loss derives from cooling and steam condensation prior low-temperature separation of $\mathrm{CO}_{2}$ from the retentate and $\mathrm{H}_{2}$ from the sweep steam in the permeate. Here, $\mathrm{CO}_{2}$ separation can be optimized, investigating different options such as the PSA or innovative approaches based on regenerative $\mathrm{CO}_{2}$ sorption at relatively high temperatures $\left(>300^{\circ} \mathrm{C}\right)$ : in this latter case, it will be possible to avoid condensation of residual steam in the retentate and allow its recirculation (with residual $\mathrm{CH}_{4}$ and $\mathrm{H}_{2}$ ) to the reactor, thus increasing the overall efficiency of the SMR process.

Operating pressures in both reaction and permeate sides of the reformer (assumed 10.5 and 1.4 bar in the 
preliminary layout) can be optimized too in order to minimize the amount of sweep steam to be generated and downstream condensed for hydrogen removal.

Finally, it is worth underlying that the proposed flowsheet implies relevant power consumption $(\sim 430 \mathrm{kWe}$ for a $1,500 \mathrm{Nm}^{3} / \mathrm{h}$ SMR plant) being the second highest operating cost (after methane feedstock), which can also be reduced with an optimized integration of the SMR plant with a hybrid CST/PV plant [8].

\section{Conclusions}

In this paper, an innovative approach to solar steam reforming of (bio)methane is presented. This process makes use of a molten salt mixture up to $550^{\circ} \mathrm{C}$ as solar heat transfer fluid and heat storage medium. Research, development and demonstration activities carried out by ENEA led to the experimental validation of the single units of the process: the concentrating solar system with heat storage and steam generator have been demonstrated to the pre-commercial scale, while the solar back-up unit and the steam reforming reactor have been experimentally validated at the pilot scale in a molten salt experimental loop at the ENEA-Casaccia research center. After experimental validation, techno-economic studies have been carried out to assess the solar reforming technology on commercial scale and exploitation opportunities have been analysed. Results show the interesting opportunities for solar SMR to reach the target of $2 € / \mathrm{kg}$ for green hydrogen production.

This research has been initially funded through the FCH JU project CoMETHy (Compact Multifuel-Energy To Hydrogen converter, Grant Agreement n. 279075), and the 7FP projects Hysol (Innovative Configuration for a Fully Renewable Hybrid
CSP Plant, Grant Agreement n.308912) and MATS (Multipurpose Applications by Thermodynamic Solar, Grant Agreement n. 268219). Experimental results have been further analysed in the project 1.9 "Concentrating Solar Power" and 1.2 "Energy storage", under the "Electric System Research" program 2019-2021, with the financial support of Italian Ministry for Ecological Transition.

\section{References}

1. M. van de Voorde. "Hydrogen Production and Energy Transition, Volume 1", De Gruyter (2021). https://doi.org/10.1515/9783110596250.

2. A. Giaconia, M. De Falco, G. Caputo, R. Grena, P. Tarquini, L. Marrelli. AIChE J., 54, 1932 (2008). https://doi.org/10.1002/aic.11510.

3. A. Giaconia, G. Monteleone, B. Morico, et al. Energy $\begin{array}{llll}\text { Procedia, } & 69, & 1750 & \text { (2015). }\end{array}$ https://doi.org/10.1016/j.egypro.2015.03.144.

4. A. Giaconia, G. Iaquaniello, G. Caputo, B. Morico, A. Salladini, L. Turchetti, G. Monteleone, A. Giannini, E. Palo. Int. J. Hydrogen Energy, 45, 33088 (2020). https://doi.org/10.1016/j.ijhydene.2020.09.070

5. A. Giaconia, I. Balog, G. Caputo. Energies. 14, 7652 (2021). https://doi.org/10.3390/en14227652.

6. A. Giaconia, G. Iaquaniello, A. Amin Metwally, G. Caputo, I. Balog. Solar Energy. 211, 622 (2020). https://doi.org/10.1016/j.solener.2020.09.091.

7. A. Giaconia, G. Iaquaniello, B. Morico, A. Salladini, E. Palo. Int. J. Hydrogen Energy, 46, 35172 (2021). https://doi.org/10.1016/j.ijhydene.2021.08.096.

8. A. Giaconia, R. Grena. Solar Energy. 2021, 224, 159 (2021) https://doi.org/10.1016/j.solener.2021.05.043. 